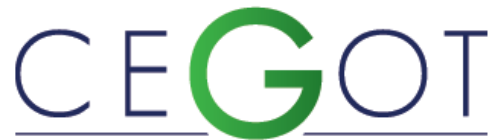

Centro de Estudos de Geografia e Ordenamento do Território
Geografia e Ordenamento do Território, Revista Eletrónica Centro de Estudos de Geografia e Ordenamento do Território http://cegot.org

KNEIB, ERIKA

Universidade Federal de Goiás, Programa de Pós Graduação Projeto e Cidade, Faculdade de Artes Visuais, Campus

Samambaia

Rua 13, 145, apto 1802, Jardim Goiás, Goiânia, Goiás, Brasil, CEP 74810-170 erikacristine.st@gmail.com

Neto, WILSON

Universidade Federal de Goiás, Programa de Pós Graduação em Geografia, Instituto de Estudos Socioambientais, Campus Samambaia

CEP 74690-900, Goiânia, Goiás, Brasil

wilsonlopesmneto@gmail.com

\title{
Mobilidade e planejamento metropolitano no Brasil: o caso da Região Metropolitana de Goiânia
}

Mobility and planning in metropolitan level in Brazil: the case of the Metropolitan Region of Goiânia

Referência: Kneib, Erika; Neto, Wilson (2018). Mobilidade e planejamento metropolitano no Brasil: o caso da Região Metropolitana de Goiânia. Revista de Geografia e Ordenamento do Território (GOT), n. ${ }^{\circ} 15$ (dezembro). Centro de Estudos de Geografia e Ordenamento do Território, p. 261-286, dx.doi.org/10.17127/got/2018.15.011

\section{RESUMO}

As metrópoles brasileiras apresentam grandes desafios em relação às funções públicas comuns, nas quais se insere a mobilidade metropolitana, tornando-se urgente cumprir as determinações legais de elaboração de um Plano de Desenvolvimento Integrado. Neste contexto, o presente artigo tem como objetivo apresentar o panorama da mobilidade na Região Metropolitana de Goiânia, estado de Goiás, no Brasil, como base para um diagnóstico do seu Plano. Como metodologia, adota-se pesquisa bibliográfica e qualiquantitativa, utilizando-se o Sistema de informações Geográficas para manipulação e espacialização de dados. Como principais resultados, o panorama, além de contribuir para conformar um diagnóstico para o plano, permite compreender o tema e elencar suas potencialidades e fragilidades, podendo inspirar outras regiões em fase de planejamento.

Palavras-chave: mobilidade urbana, região metropolitana, plano de desenvolvimento integrado, panorama

\section{ABSTRACT}

The Brazilian metropolises present big challenges related to public common functions, in which urban mobility is inserted, making it urgent to comply the legal determinations of elaborating an Integrated Development Plan. In this context, this paper aims to present the panorama of mobility in the Metropolitan Region of Goiânia, state of Goiás, in Brazil, as a basis to the plan diagnosis. As methodology, bibliographical and qualiquantitative research are adopted, using also the Geographical Information System (GIS) for data manipulation and spatialization. As main results, the panorama, besides contributing to the plan 
diagnosis, allows to understand the subject and to highlight its potentialities and fragilities, being able to inspire other regions in their planning stage.

Keywords: urban mobility, metropolitan region, integrated development plan, panorama

\section{Introdução}

No Brasil, o crescimento das cidades, da população urbana e o incentivo à aquisição e utilização do veículo motorizado individual - para quaisquer deslocamentos nas cidades têm levado à degradação da qualidade de vida urbana, com consequentes e crescentes desafios de planejamento e gestão. Não bastassem os desafios relativos à escala do município, muitas áreas urbanas se aglomeraram e se desenvolveram como um único organismo, com uma dinâmica em rede apesar de gestões diferenciadas, formando as regiões metropolitanas (RM), locais onde são potencializadas as trocas e relações, ao mesmo tempo em que crescem os desafios sobre integração das políticas públicas.

Pyca (2013) destaca o potencial das metrópoles, segundo o qual, são pontos de crescimento dinâmico, norteando a economia nacional, capazes de desenvolver funções políticas, culturais, financeiras e econômicas em níveis superiores a outras localidades, devido à proximidade espacial e interação das cidades que a constituem.

Sobre o processo de metropolização, segundo IPEA (2010), este caracteriza-se por um processo de integração do território a partir de uma cidade-núcleo, configurando um território ampliado, em que se compartilha um conjunto de funções de interesse comum. Tais funções podem ser entendidas como políticas públicas inviáveis de serem realizadas por um único município ou, ainda, que causem impactos em municípios limítrofes (Brasil, 2015), a exemplo de transporte e mobilidade urbana, saneamento ambiental, desenvolvimento urbano, dentre outras.

Apesar de um processo de metropolização constatado em diversas regiões brasileiras, é fato um aspecto comum a todas: apesar de existirem legalmente, na prática ainda não funcionam (GOUVÊA, 2005). O que se verifica de forma geral nas regiões metropolitanas brasileiras é que as gestões municipais desenvolvem ações de gestão desarticuladas, o que demonstra a falta de integração de políticas, em especial as de planejamento urbano. No âmbito da mobilidade, este fato leva ao agravamento do espraiamento urbano, com 
consequente majoração dos deslocamentos pendulares, tema este investigado por diversos trabalhos, dada sua relevância e complexidade de solução (MOURA et al., 2005; LOBO et al., 2015).

$\mathrm{Na}$ tentativa de minimizar as consequências negativas de processos como os citados, passou a ser exigido por lei no Brasil que cidades, regiões metropolitanas e estados elaborem seus planos diretores municipais, planos de mobilidade e, mais recentemente, o Plano de Desenvolvimento Urbano Integrado (PDUI). Este último, instituído pelo Estatuto da Metrópole, Lei Federal 13.809/2015 (BRASIL, 2015), consiste em um instrumento que deve estabelecer as diretrizes para funções públicas de interesse comum, com foco nas diretrizes para o desenvolvimento urbano da região metropolitana, a partir de um processo permanente de planejamento. No processo de elaboração do PDUI, dois elementos merecem um grande destaque, a partir do conteúdo da citada Lei, inseridos no contexto brasileiro: a necessidade de efetivar o planejamento integrado - que envolve o governo estadual e os governos municipais inseridos na RM, prioritariamente no âmbito executivo e legislativo, visando romper um padrão existente até então de processos de planejamento e gestão municipais desarticulados; a necessidade de estabelecimento de mecanismos de governança interfederativa, entendida como o compartilhamento de responsabilidades e ações entre tais entes, relativos à organização, planejamento e execução de funções públicas de interesse comum.

Dentre as funções públicas de interesse comum, uma constitui o foco deste trabalho: a mobilidade metropolitana. Por mobilidade, cabe reforçar a definição trazida pela federal brasileira, que a define como a "condição em que se realizam os deslocamentos de pessoas e cargas no espaço urbano" (BRASIL, 2012, art. $4^{\circ}$ ). Diversos autores destacam e ratificam a importância do movimento de pessoas e bens na cidade, relacionando-o inclusive à justiça social, direito à cidade e potencial econômico (HARVEY, 1973; SOJA, 1989; PYCA, 2013).

A partir de uma intensa urbanização e interdependência entre os municípios, os limites municipais passam a ser meramente administrativos, não correspondendo aos limites das relações econômicas, sociais e culturais da RM. No âmbito da gestão da mobilidade, tal situação mostra-se particularmente problemática, pois a proximidade e conurbação entre os municípios ampliam os deslocamentos cotidianos intermunicipais em todos os modos de transporte. As prefeituras, responsáveis pelos serviços de trânsito e transportes locais, não 
conseguem prover uma infraestrutura física e de serviços para atender esta demanda (MINISTÉRIO DAS CIDADES, 2015).

Na Região Metropolitana de Goiânia (RMG), objeto do presente trabalho, a situação não é diferente: intensa urbanização e interdependência caracterizam a região formada por vinte municípios, o que provoca um número de viagens diárias entre eles que extrapola a capacidade de planejamento e de gestão da mobilidade e acessibilidade locais. De acordo com o Ministério das Cidades (2015), tal situação exige planejamento e gestão que envolva o governo estadual e os municípios com foco na provisão da mobilidade intramunicipal e intrametropolitana.

Institucionalizada pela Lei Complementar no 27, de 30 de dezembro de 1999, a RMG foi alterada pelas Leis Complementares № 78, de 25 de março de 2010, e o 87, de 7 de julho de 2011 e passou a ser constituída por vinte Municípios: Abadia de Goiás, Aparecida de Goiânia, Aragoiânia, Bela Vista de Goiás, Bonfinópolis, Brazabrantes, Caldazinha, Caturaí, Goianápolis, Goiânia, Goianira, Guapó, Hidrolândia, Inhumas, Nerópolis, Nova Veneza, Santo Antônio de Goiás, Senador Canedo, Terezópolis de Goiás e Trindade, totalizando mais de 2,5 milhões de habitantes (IBGE, 2016).

Na RMG, apenas 16 dos 20 municípios possuem Plano Diretor Municipal; e nenhum município possui Plano de Mobilidade, nem mesmo a capital, Goiânia. No ano de 2014, a RMG iniciou a elaboração de um Plano Metropolitano. Este processo foi paralisado e posteriormente retomado, em 2017, e passou a ser denominado de Plano de Desenvolvimento Urbano Integrado - PDUI, procurando adequar-se e atender à determinação do Estatuto da Metrópole (BRASIL, 2015). O PDUI visa o desenvolvimento da RMG, com base no reordenamento do território, focando as políticas públicas de interesse comum aos municípios (UFG e SECIMA, 2017), sendo que a mobilidade metropolitana constitui uma destas políticas.

A última pesquisa origem e destino (OD) foi realizada no ano 2000 na RMG e identificou 2,2 milhões de viagens diárias. Desse total, 36\% dos deslocamentos já eram realizados por modo motorizado individual, $30 \%$ por modo coletivo público, $26 \%$ por modo não motorizado a pé, $6 \%$ por modo não motorizado bicicleta e $2 \%$ por modo motorizado fretado (CMTC, 2007). Cabe destacar ainda que a RMG não dispõe de uma pesquisa OD atual, o 
que seria de fundamental importância para o PDUI e, também, para o desenvolvimento de um plano de mobilidade.

Em meio aos desafios da mobilidade metropolitana; à necessidade de planejamento integrado nas RM brasileiras; à determinação legal para elaboração e aprovação do PDUI instrumento recente, sobre o qual as RM estão em fase de elaboração e em processo de aprendizagem; e do desafio de diagnosticar e definir diretrizes para uma mobilidade metropolitana sem uma pesquisa origem e destino atualizada, o presente artigo tem como objetivo apresentar o panorama da mobilidade metropolitana na Região Metropolitana de Goiânia. Como metodologia, adota-se pesquisa bibliográfica e qualiquantitativa, utilizando-se bases de dados diversas existentes, assim como o Sistema de informações Geográficas - SIG e suas ferramentas para manipulação e espacialização de dados. Entendese o panorama como uma situação geral, ou uma visão de conjunto. Para efeito de análise, a mobilidade metropolitana é dividida em subtemas: dinâmica metropolitana, transporte coletivo, motorizado individual e cargas, modos não motorizados e sistema viário. Tais subtemas, quando analisados de forma integrada, permitem obter o desejado panorama da mobilidade na RMG.

Como principais resultados, destaca-se que o panorama apresentado, além de contribuir para conformar um diagnóstico para o PDUI, permite elencar potencialidades e fragilidades de cada um dos subtemas, elementos fundamentais para a compreensão da mobilidade metropolitana na RMG, assim como para inspirar regiões que estejam em fase de elaboração de seus PDUI.

\section{Caracterização da mobilidade na RMG}

A população que reside em RM tem enfrentado um cotidiano indesejável: índices crescentes de congestionamentos, aumento da poluição em função do uso excessivo de automóveis, degradação ambiental, prejuízos econômicos e sociais provenientes da acidentalidade viária, além do estresse. Tal assertiva é corroborada por estudos recentes (CNT e NTU 2017), que revelam que o transporte consiste em um dos principais problemas urbanos dos 
municípios brasileiros. Os problemas de mobilidade têm sido evidenciados principalmente em aglomerados urbanos com população superior a um milhão de habitantes. Somam-se a esses problemas outros que envolvem a segurança/violência nas metrópoles, o acesso e a qualidade do sistema de saúde e a conjuntura política e econômica que atualmente resulta em altos índices de desemprego que afetam, sobretudo, indivíduos que residem nas cidades.

Com relação aos impactos sociais e econômicos da mobilidade na RMG, cabe citar o estudo da FIRJAN (2015), segundo o qual cerca de quatrocentas mil pessoas na RMG gastaram mais de 120 minutos em seus deslocamentos pendulares em 2012, o que corresponde a um custo aproximado de 1,5 bilhão de reais ao ano. Isso reflete os altos custos do modelo adotado que privilegia o transporte motorizado individual. Essa situação salienta a necessidade da busca de um novo paradigma de mobilidade para a RMG.

A escala metropolitana pressupõe uma investigação primaz dos modos motorizados, devido às especificidades dos deslocamentos intrametropolitanos e intermunicipais (KNEIB, 2016). São esses deslocamentos os prioritariamente investigados, já que as viagens que envolvem a RMG são precipuamente de caráter regional, ou seja, são deslocamentos que precisam vencer médias e grandes distâncias. No entanto, em complemento, a infraestrutura relacionada ao transporte de cargas e a viagens realizadas por modos não motorizados (a pé e bicicleta) também é investigada. É fundamental e necessário entender o potencial dos deslocamentos a pé e por bicicleta a fim de viabilizar o uso desses modos de transporte na região de estudo quando possível cumprindo, assim, a legislação federal que determina a priorização dos modos não motorizados sobre os motorizados (BRASIL, 2012) e, também, do transporte coletivo sobre o individual motorizado, mesmo nos deslocamentos metropolitanos.

Conforme destacado na introdução, para efeito de análise, a mobilidade metropolitana na RMG é dividida em subtemas: dinâmica metropolitana, transporte coletivo, motorizado individual e cargas, modos não motorizados e sistema viário. Nestas análises, o SIG e suas ferramentas são utilizadas para manipulação e espacialização de dados. Assim sendo, cada subtema contemplou determinados materiais e métodos para sua caracterização e análise. 


\subsection{Mobilidade na RMG: dinâmica metropolitana}

A dinâmica metropolitana pode ser compreendida a partir dos fluxos de pessoas entre os municípios. Para isso, é fundamental investigar os deslocamentos, com ênfase nas viagens pendulares. As viagens pendulares, normalmente concentradas nos horários de pico, sobrecarregam os sistemas de transporte e constituem uma questão relevante no processo de planejamento. São derivadas da combinação de dois elementos: a distribuição das atividades no território e os sistemas de transporte. Assim sendo, uma estrutura territorial descentralizada, que busca uma policentralidade equilibrada, é uma das grandes respostas a tal questão (IMTT, 2011; KNEIB, 2014).

Nesse contexto, cabe enfatizar que uma meta desejada para as regiões metropolitanas se organizarem, nas diversas escalas, é ter como base uma rede de centralidades planejadas, ativas e dinâmicas, em função das quais se organizam os fluxos de pessoas e bens (IMTT, 2011; KNEIB, 2014). Tal rede de centralidades deve ser apoiada por uma rede viária hierarquizada funcionalmente, desde o nível municipal ao regional. Esse fato justifica-se porque as centralidades serão uma das grandes responsáveis por caracterizar os fluxos urbanos e metropolitanos, corroborando a estreita relação entre os sistemas de transporte e o uso do solo. Centralidades planejadas, com atividades diversas, criam oportunidades para que as pessoas desenvolvam suas atividades em locais próximos, evitando longos deslocamentos pendulares diários, como os observados na RMG.

Conforme destacado anteriormente, não existe uma pesquisa OD recente para a região. Assim, para a análise da mobilidade, tornou-se fundamental a base de dados da pesquisa que resultou na publicação 'Arranjos populacionais e concentrações urbanas no Brasil', do Instituto Brasileiro de Geografia e Estatística - IBGE (2016). Com essa base de dados foi possível verificar diferentes níveis de integração entre os municípios da RMG, identificados e mensurados a partir da análise de deslocamentos pendulares por motivo de trabalho e estudo. Cabe destacar a importância de todos os tipos de deslocamento para análise da dinâmica metropolitana, incluindo os demais motivos de viagem (lazer, compras, turismo, etc.) como base para o planejamento. Porém, conforme descrito inicialmente, a RMG não dispõe de tal base de dados atualizada, fato que levou à utilização das informações do IBGE (2016). 
Na Figura 1, é possível visualizar os fluxos dos deslocamentos pendulares entre os municípios da RMG, assim como a mancha urbana e a densidade populacional dos municípios. As linhas dos fluxos representam a soma do número de pessoas que se deslocam entre os municípios e fundamenta-se no conceito de ligação entre os municípios. Compreendida dessa maneira, a ligação expressa a integração entre os municípios em função dos movimentos pendulares por motivo de trabalho e/ou estudo, e caracteriza-se o que foi denominado de dinâmica metropolitana. A densidade populacional foi calculada com base na área total do município e o número de habitantes do mesmo. Percebe-se que Goiânia, Aparecida de Goiânia, Senador Canedo e Trindade apresentam os maiores pesos populacionais. Esses três municípios também são caracterizados por constituírem e/ou conterem as centralidades urbanas que polarizam os demais. É a partir desses municípios que ocorre o espraiamento da mancha urbana.

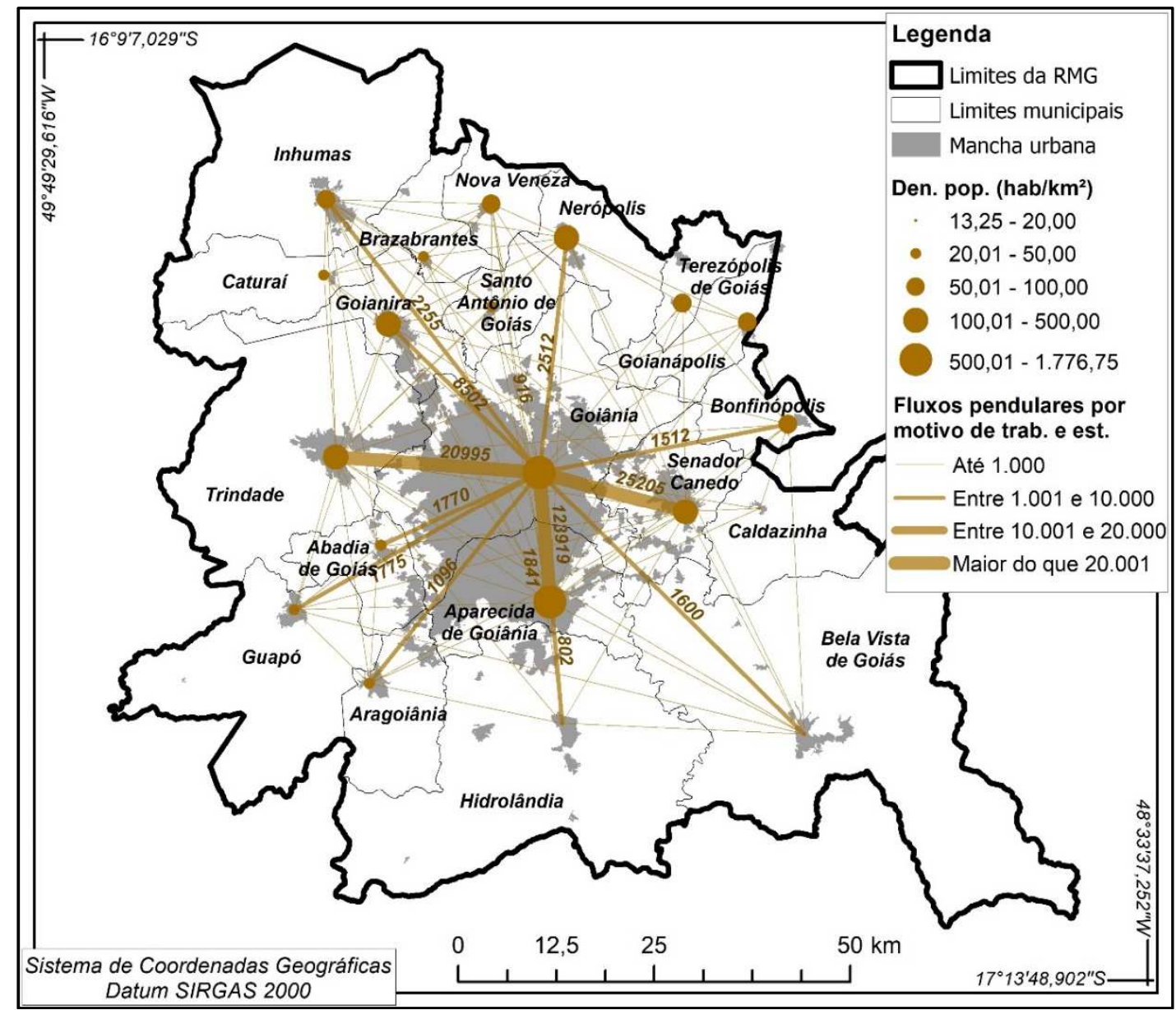

Figura 1: Fluxos pendulares por motivo trabalho e/ou estudo nos municípios da RMG, mancha urbana e densidade populacional

Fonte: Autores, elaborado com base nos dados do IBGE (2016) 
Quando se compara a porcentagem de pessoas que se deslocam dos municípios de residência para estudar e/ou trabalhar em outros municípios e o número de pessoas que estudam e/ou trabalham no município de residência (Figura 2), é possível identificar que Abadia de Goiás, Aparecida de Goiânia, Goianira e Senador Canedo são os que possuem os maiores percentuais, superiores a $30 \%$ de suas populações. Ressalta-se que esse percentual pode indicar a necessidade de constituição de centralidades nesses municípios que ofereçam para população local oferta de estabelecimentos e oportunidades de estudo e trabalho, evitando assim, o elevado índice de deslocamento pendular de seus habitantes.

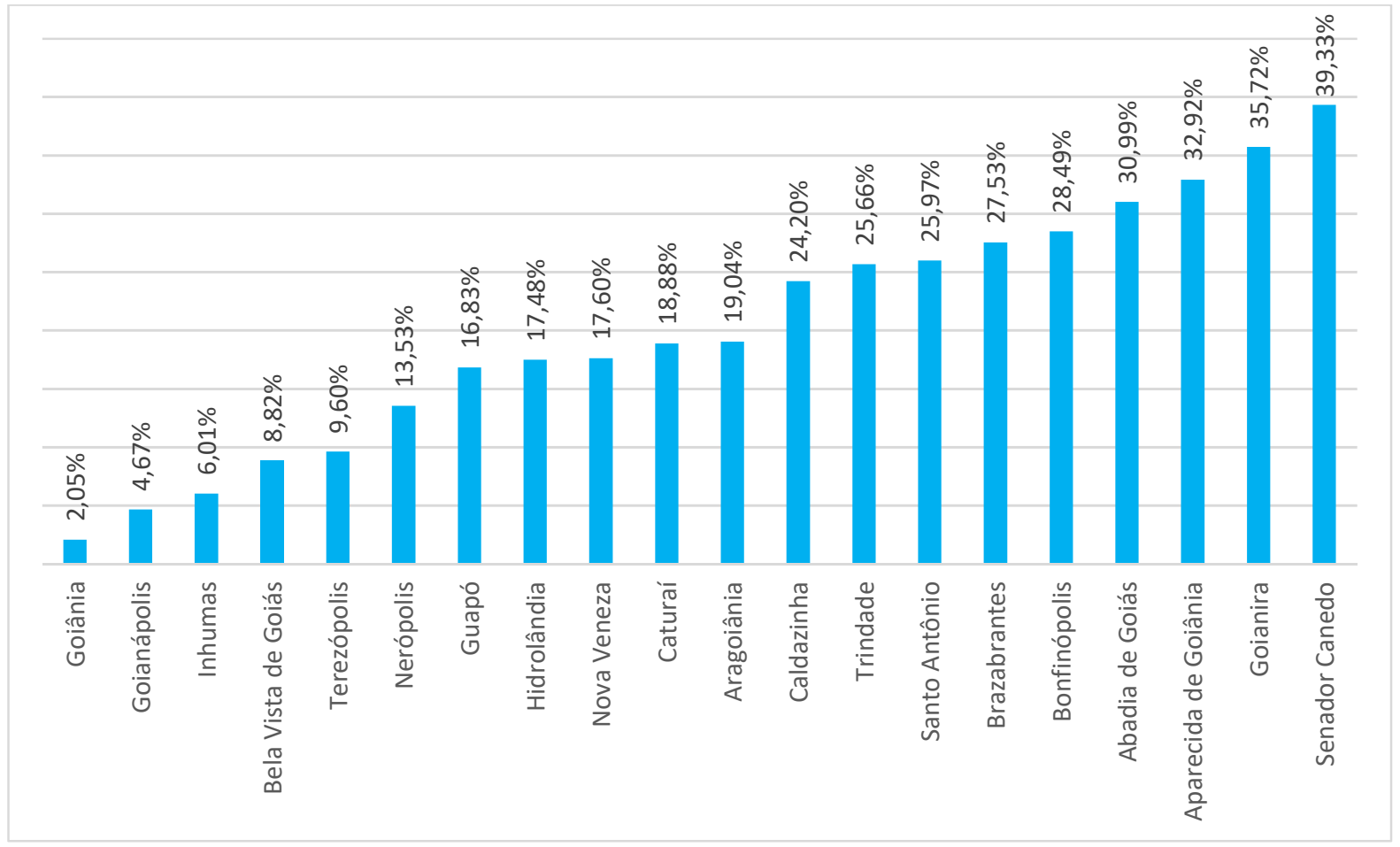

Figura 2: Movimento pendular: porcentagem de pessoas que se deslocam dos municípios de residência para estudar e/ou trabalhar em outros municípios em relação ao número de pessoas que estudam ou trabalham no município de residência

Fonte: Autores, elaborado com base nos dados do IBGE (2016)

A análise do número de pessoas que os municípios recebem por motivo de trabalho e/ou estudo (Figura 3) fornece a dimensão da polarização da capital, Goiânia, em relação aos demais. A capital recebe cerca de 176.112 pessoas vindas de outros municípios por motivo de trabalho e/ou estudo. O número representa $86,63 \%$ de toda a população da RMG, que se desloca pendularmente por esse motivo. Goianira, Inhumas, Senador Canedo, Trindade e Aparecida de Goiânia recebem contingentes menores que dezesseis mil e maiores que mil 
pessoas. Os outros municípios recebem contingentes menores que mil pessoas. Mostra-se evidente, então, que Goiânia polariza os outros municípios da RMG em diferentes níveis.

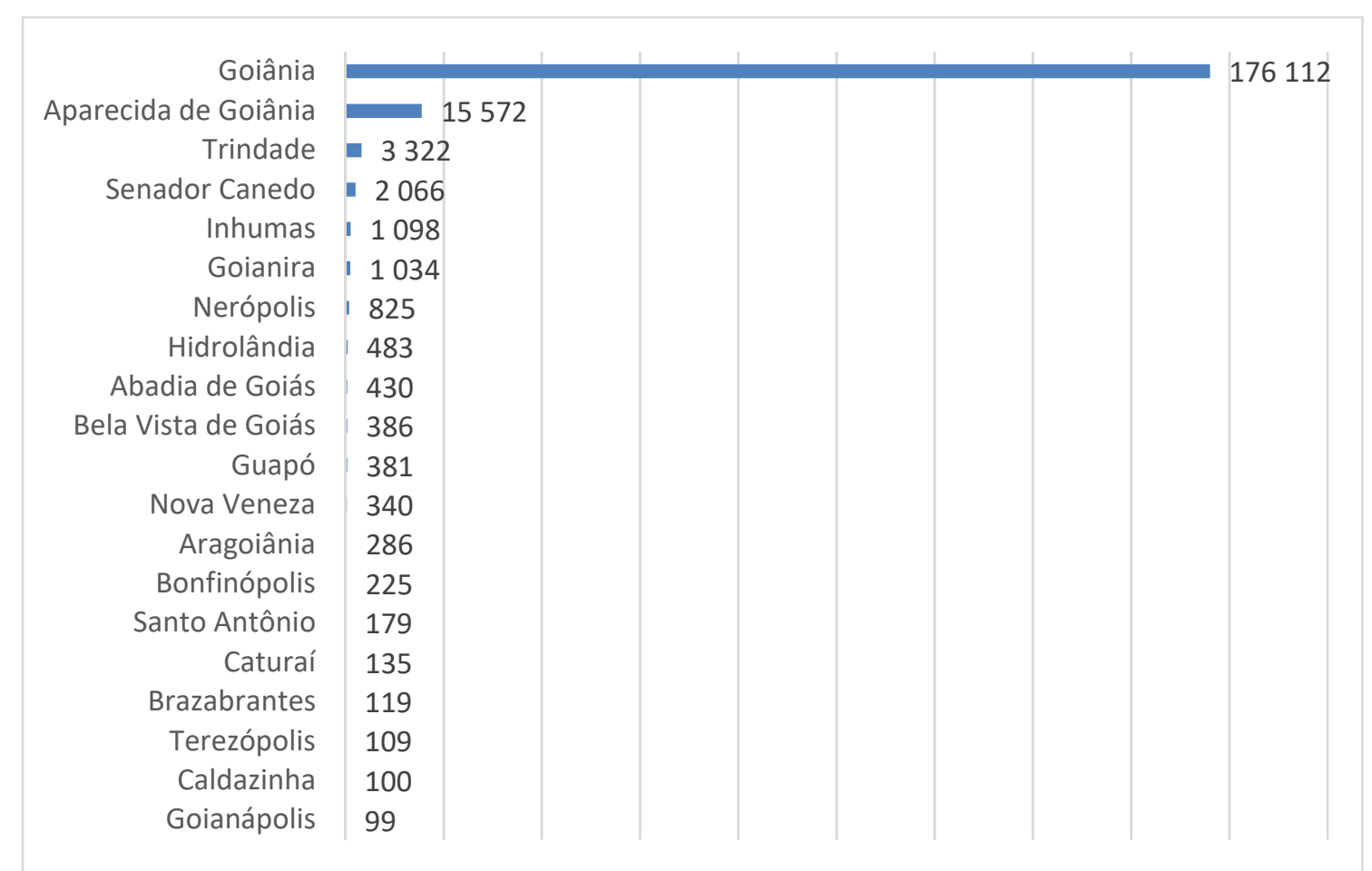

Figura 3: Movimento pendular: número de pessoas que os municípios recebem por motivo trabalho e/ou estudo

Fonte: Autores, elaborado com base nos dados do IBGE (2016)

\subsection{Mobilidade na RMG: transporte coletivo}

A Constituição Federal (BRASIL, 1988) define o transporte coletivo urbano como um serviço público essencial, que deve ser provido diretamente pelo Estado ou por particulares, sob delegação do poder público responsável (União, estados ou municípios). Apesar da prioridade comumente concedida aos modos motorizados individuais (carros e motos), o transporte coletivo ainda supera a utilização do modo individual motorizado na maior parte das cidades brasileiras (CNT E NTU, 2017). Contudo, essa realidade vem mudando. De acordo com dados da NTU (2016), houve uma perda de 9\% na demanda de passageiros de transporte público no Brasil entre 2014 e 2015. Tais números significam uma perda de demanda equivalente a 3,22 milhões de usuários pagantes por dia. Como se não bastassem as dificuldades relacionadas à falta de priorização, investimentos e infraestrutura dedicada a esse modo, o transporte coletivo enfrenta dois sérios problemas, que extrapolam o sistema e o serviço, mas que o impactam diretamente: i) espraiamento urbano; ii) a falta de integração da política de mobilidade com a política de uso e ocupação do solo. 
O espraiamento urbano necessita ser regulado por outros instrumentos de políticas setoriais, além do próprio Plano Diretor e dos planos setoriais, como o de habitação. Todavia, ao se considerar os Planos de Mobilidade, conforme a Política Nacional de Mobilidade (Brasil, 2012), estes pouco podem colaborar no controle do espraiamento, o que se deve ao fato de serem reativos e, nesse sentido, não podem por força da lei, tratar de uso e ocupação do solo. Nesse contexto, o Plano de Desenvolvimento Urbano Integrado (PDUI) passa a ter papel preponderante na gestão territorial metropolitana, relacionado ao espraiamento e seus impactos na mobilidade metropolitana e urbana.

No contexto do planejamento e gestão territorial, cabe enfatizar o modelo denominado Desenvolvimento Orientado ao Transporte (DOT). Este prioriza um transporte coletivo de alta qualidade, em conjunto com um planejamento e uma concepção de características de uso e ocupação do solo que o apoiem e facilitem, em conjunto com o pedestre e a bicicleta. O Instituto de Políticas de Transporte \& Desenvolvimento (ITDP) desenvolveu um material segundo o qual a avaliação do DOT baseia-se em oito princípios: compactar, conectar, adensar, usar transporte público, misturar, pedalar, caminhar e mudar (mudar o modelo baseado nos automóveis) (ITDP, 2013).

\section{A Rede Metropolitana de Transportes coletivos da RMG}

A Lei Complementar n²7/1999 (Goiás, 1999), que instituiu a RM de Goiânia, permitiu a existência de um efetivo sistema metropolitano de transportes com linhas planejadas e integradas, com a finalidade de garantir o funcionamento do transporte coletivo em toda a região metropolitana. Rompendo com uma tradição nacional de contar com sistemas distintos de transportes municipais (providos e geridos por cada município) e intermunicipais (providos e geridos pelo estado), na RMG estabeleceu-se um sistema unificado, com apenas uma rede de transportes que conecta toda a região.

O serviço de transporte público coletivo de passageiros da RMG estrutura-se a partir de uma rede de serviços denominada Rede Metropolitana de Transportes Coletivos (RMTC), cujo objetivo é a promoção da acessibilidade, da universalidade e da mobilidade da população de dezoito dos vinte municípios que conformam a RMG (RMTC, 2017a). A RMTC engloba tudo aquilo que conforma um sistema de transporte coletivo: em relação à dimensão físicoespacial destacam-se as vias, os terminais, os corredores; em relação à logística destacam-se 
as linhas, os trajetos, os horários, os meios e as formas de integração; em relação ao modelo de operação e acesso dos passageiros ao serviço destacam-se as tarifas, as formas de pagamento, e as formas de controle.

Segundo a CMTC (2013a), o modelo operacional da RMTC é, em grande parte da rede, tronco-alimentado. Nesse tipo de modelo, as linhas alimentadoras fazem a ligação dos bairros com os locais de integração, e as linhas troncais (eixo) distribuem as viagens em áreas centrais, corredores e polos de atração de viagens. Dividida em quatro áreas operacionais, a rede opera com 302 linhas. Cerca de 259 mil pessoas utilizam diariamente o serviço, o que representa em torno de $10 \%$ da população residente na RMG (RMTC, 2017a). Com relação à demanda, segundo dados de 2017, a RMTC realiza em um dia útil, em média, 584 mil viagens. No sábado esse número é de 234 mil e, no domingo, de 123 mil (RMTC, 2017a). Todavia, o cenário não se mostra otimista. A perda de competitividade do transporte coletivo em relação ao modo individual - provocada por fatores como ausência de priorização e investimento público no sistema de transporte coletivo, aliada à crescente dispersão das ocupações das cidades - reflete em uma perda crescente da demanda. Em 2016, a demanda do transporte coletivo da RMTC foi de 173.954 .105 viagens. Isso representa uma queda de demanda de mais de $12 \%$ em comparação com o ano anterior, 2015, cuja demanda alcançou mais de 196.356.654 (RMTC, 2017a).

Com relação à tarifa, o sistema opera em uma tarifa única e integrada. O usuário pagante é o único financiador, não havendo recursos extratarifários para operação do sistema. Com a tarifa única, o usuário pode percorrer qualquer distância ou acessar qualquer município da RMG, com o pagamento do mesmo valor, a partir de um subsídio cruzado interno ${ }^{1}$. Trata-se de um benefício implementado inicialmente para a integração e desenvolvimento da RM. Todavia, devido à ausência de uma política tarifária adequada, capaz de subsidiar o usuário de longa distância, a tarifa única passou a incentivar as longas viagens, favoreceu a ocupação urbana em áreas distantes e, consequentemente, passou a desestimular o usuário de curta e média distância, assim como prejudicar a sustentabilidade financeira do sistema.

\footnotetext{
${ }^{1}$ No contexto do sistema de transporte público coletivo, o subsídio pode ser direto, via recursos públicos; ou cruzado, interno ao próprio sistema, que consiste em incluir o custo dos usuários não pagantes na composição da tarifa. Segundo Lorenzetti (2003) Esta segunda opção, embora bastante utilizada, revela-se perversa, uma vez que o ônus do benefício vai ser rateado pelo conjunto dos usuários pagantes, que muitas vezes não possuem condições para tal.
} 
O preço da tarifa de transporte público deve refletir ao máximo a qualidade dos serviços prestados. Contudo, alguns fatores relatados merecem destaque na RMG: a) leis brasileiras determinam descontos e gratuidades para várias categorias, como idosos, deficientes, estudantes, que necessitam ser absorvidos pela tarifa (e pelo usuário pagante), e caracterizam um subsídio cruzado interno, com um universo próximo de $25 \%$ dos usuários; b) um repasse realizado ao órgão gestor, equivalente a $1 \%$, que onera a tarifa; c) a falta de infraestrutura prioritária, como corredores, que força os ônibus a ficarem presos nos congestionamentos junto com os automóveis, comprometendo sua velocidade operacional, regularidade e confiabilidade, bem como impactando os custos do serviço; d) o espraiamento urbano, no qual ocupações, normalmente de baixa demanda, geram a necessidade de mais viagens e viagens em distâncias cada vez mais longas por transporte coletivo, o que onera o serviço e acaba gerando uma tarifa mais cara. Tais fatores vêm afetando diretamente a qualidade da prestação do serviço na RMG.

Além dos itens mencionados anteriormente, cabe destacar que o modelo de financiamento do transporte coletivo na RMG, baseado exclusivamente na receita tarifária, apresenta dificuldades. De modo geral, são poucos os casos de recursos extratarifários a financiar o transporte coletivo no Brasil, ao contrário do que ocorre nos países da Europa, da América do Norte ou mesmo da América do Sul, nos quais os sistemas de transporte recebem recursos diretamente dos governos, em seus diversos níveis, provenientes ou não de impostos específicos, visando a redução da tarifa e a melhoria da qualidade (IPEA, 2013).

Em meio aos elementos abordados, a Figura 4 apresenta a caracterização da oferta de transporte coletivo na RMTC. A oferta de transporte coletivo depende de dois elementos: a disponibilidade de linhas de ônibus e a frequência das linhas ao longo de determinados intervalos de tempo. Assim, a oferta pode ser compreendida como expressão de uma relação que se dá no espaço e no tempo, pois a disponibilidade de linhas é mensurada por meio de sua distribuição espacial; a frequência é mensurada por meio da análise do número de vezes que uma linha passa em determinado local em um dado intervalo de tempo. Para análise da oferta de TPC nos municípios da RMG, realizou-se o cálculo da densidade de linhas de ônibus e normalizaram-se os valores dividindo a densidade de linhas pelo número de viagens de cada linha de ônibus em um dia útil. 
Ressalta-se que as classes de oferta foram estabelecidas com base nas quebras-naturais. Essas classes são estabelecidas utilizando o método estatístico denominado Otimização de Jenk para classificar os atributos. Este algoritmo agrupa os atributos baseados na distribuição dos dados e visa reduzir ou maximizar a variância nestes grupos (ESRI, 2017). Assim, os valores da oferta são divididos em classes cujos limites são estabelecidos onde existem diferenças relativamente grandes nos valores dos dados.

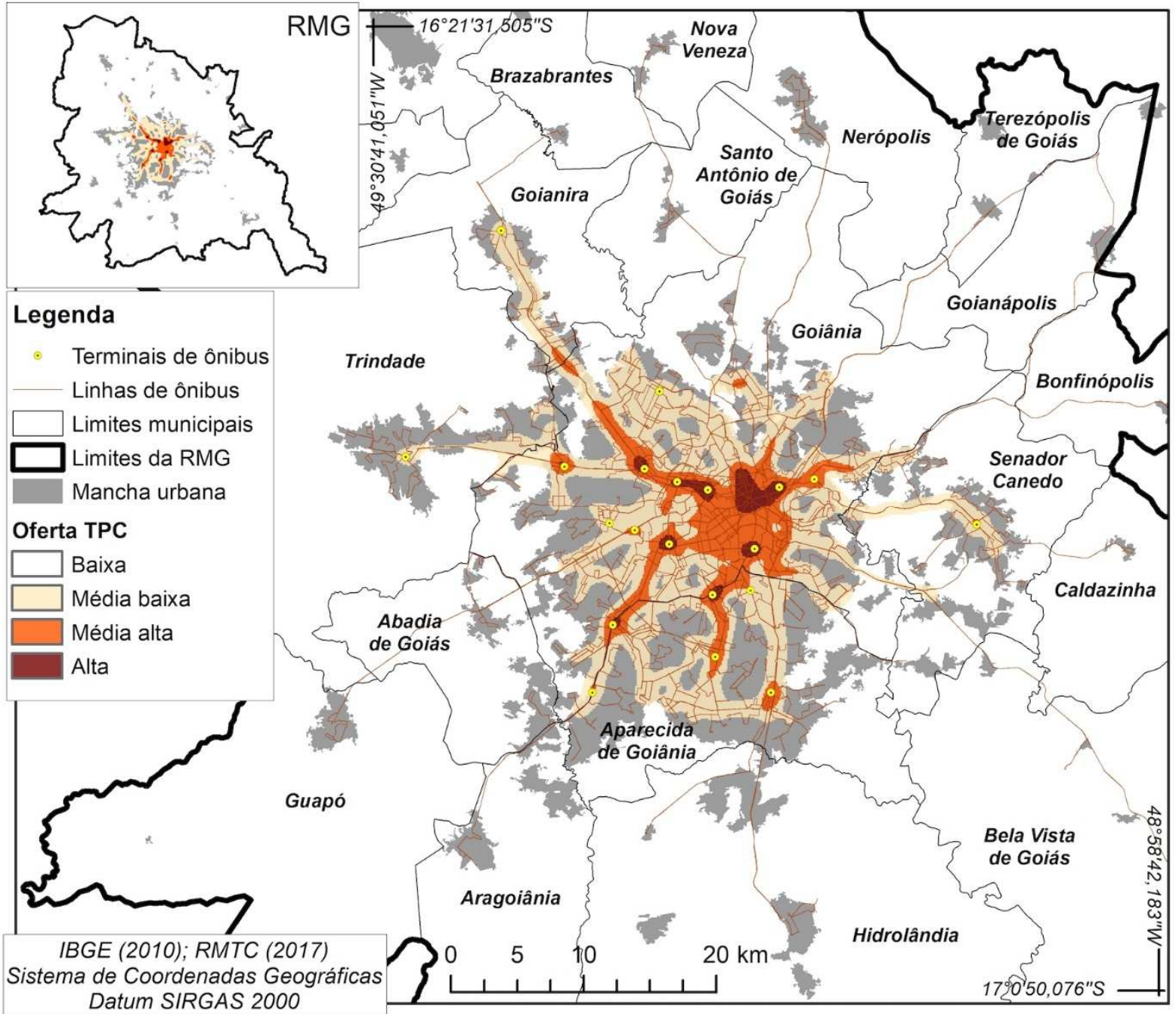

Figura 4: Oferta de transporte coletivo na RMG Fonte: Autores, com base em dados da RMTC (2017)

A partir da Figura 4, observa-se que a oferta de transporte coletivo é altamente concentrada na porção centro-sul de Goiânia, em direção ao município de Aparecida de Goiânia, e no sentido leste-oeste da RMG, entre Senador Canedo e Goiânia, entre Goiânia e Trindade e entre Goiânia e Goianira. Algumas áreas no interior de Aparecida de Goiânia também apresentaram alta concentração de oferta. 
O Setor Central em Goiânia é bem provido de transporte coletivo e essa oferta acompanha os eixos de destaque da estrutura viária intramunicipal. Essa alta oferta de transporte coletivo nesses eixos de importância para a RMG é inversamente proporcional à distância de Goiânia, ou seja, independentemente do eixo, a oferta de transporte coletivo se reduz à medida que a distância de Goiânia aumenta, aliada à redução das densidades populacionais. Cabe destacar a importância da articulação das políticas de mobilidade, especialmente relacionadas ao transporte coletivo, com os projetos de ocupação e expansão urbana.

\subsection{Mobilidade na RMG: motorizado individual e cargas}

Questões regulamentares e legais, como a Política Nacional de Mobilidade Urbana no Brasil (PNMU), descrita na Lei Federal 12.587/2012 (Brasil, 2012) contém diretrizes e objetivam a promoção da mobilidade sustentável. Todavia, outras medidas, principalmente de natureza econômica, têm estimulado a produção, a aquisição e o uso do transporte individual. Consequentemente, em tempos recentes, o Brasil assistiu ao aumento expressivo das taxas de motorização (ONU HABITAT, 2016).

É notório que este aumento do transporte individual acarreta efeitos negativos, como maior poluição atmosférica de gases do efeito estufa e aumento de congestionamentos, e fomento ao espraiamento urbano, que afetam negativamente a operação do transporte público. Essa degradação nas condições de mobilidade impacta o aumento dos tempos de viagem e contribui para o quadro geral de descontentamento com o transporte público e o trânsito, principalmente nas grandes cidades e regiões metropolitanas (IPEA, 2013).

A RMG segue esta lógica nacional. O crescimento expressivo da frota veicular na RMG indica o reflexo da dinâmica econômica, associada à facilidade de uso e prioridade conferida ao transporte individual motorizado sobre os demais modos na RMG. Cabe destacar os valores do crescimento nos municípios de maior porte e população, como Goiânia, Aparecida de Goiânia, Senador Canedo e Trindade (Figura 5). O crescimento da frota ajuda a compreender o aumento do uso (muitas vezes indiscriminado) desse modo motorizado individual. 


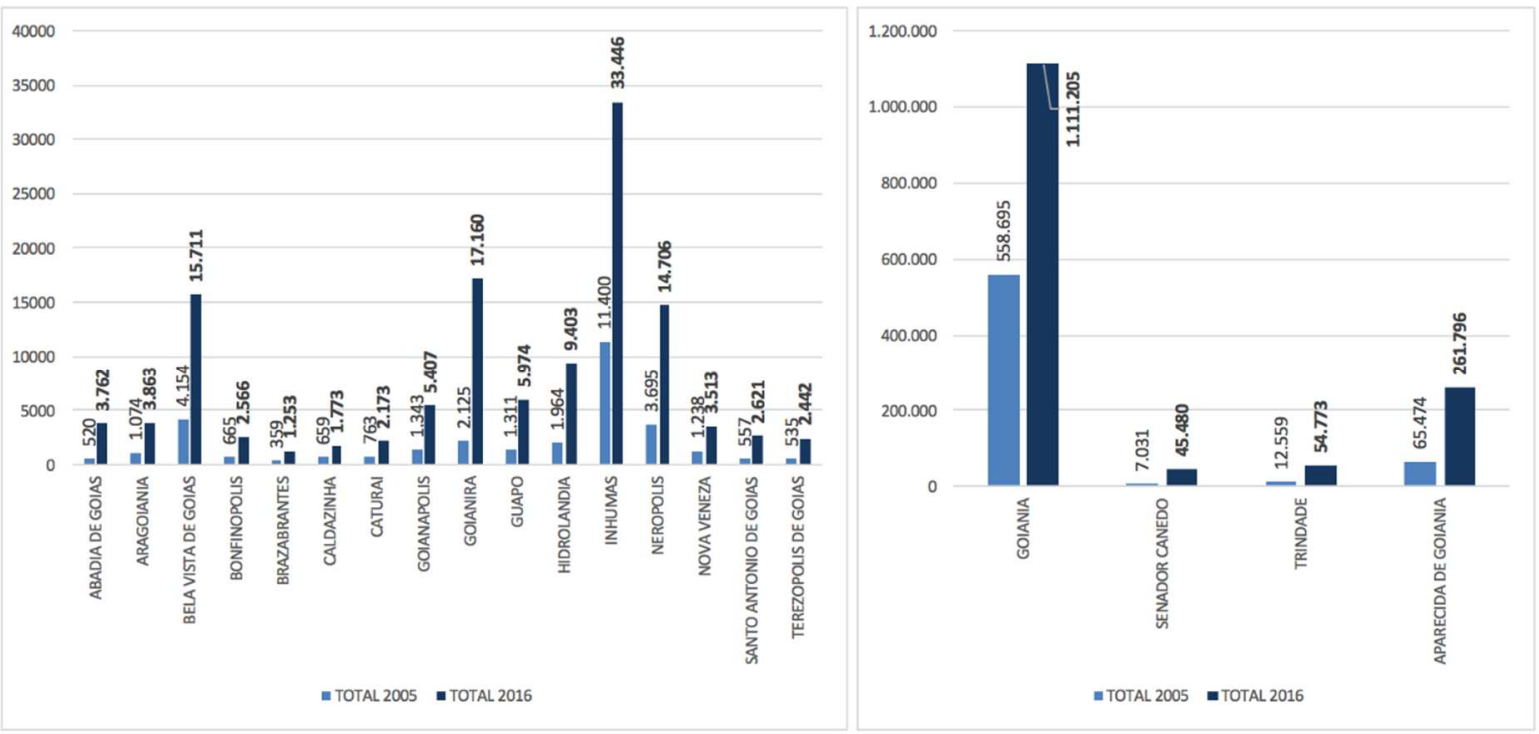

Figura 5: Comparativo do número de veículos motorizados nos municípios da RMG em 2005 e 2016 Fonte: Autores com base em dados do DENATRAN (2005 e 2016).

Com relação às cargas, destaca-se que o transporte de carga abrange as atividades necessárias à distribuição das mercadorias no espaço e é componente fundamental no processo de produção e o consumo, no grande mercado que é a Região Metropolitana. Observa-se a presença cada vez maior de fluxos de carga nas cidades, demonstrando que o transporte de carga constitui um elemento do sistema urbano, estando fortemente associado à dinâmica e à estruturação espacial das áreas metropolitanas. O desempenho dos serviços de transporte e logística impacta na eficiência, produtividade das atividades econômicas seja no âmbito regional ou local, com importantes repercussões na mobilidade metropolitana.

A RMG é cortada por eixos rodoviários de fundamental importância, como a rodovia BR-153 que integra o Norte ao Sul do País, a BR-060 que liga Goiânia ao Distrito Federal e ao Estado do Mato Grosso. Apesar do transporte ferroviário pouco utilizado no Estado, um trecho de ferrovia interliga a capital Goiânia ao Sudeste Goiano, a partir de Senador Canedo, cidade que possui grandes distribuidoras petrolíferas e abatedouros de grande porte. Outro transporte importante para a região é o poliduto da Transpetro, Paulínia - Goiânia - Brasília, que fornece quase todo o combustível a granel (cerca de 90\%) para o Centro-Oeste (Seplan, 
2010). As rodovias mencionadas, assim como sua relação com a RMG, serão detalhadas no item 2.6, que abrange o tema sistema viário metropolitano.

\subsection{Mobilidade na RMG: modos não motorizados}

Conforme descrito inicialmente, os deslocamentos entre municípios são caracterizados predominantemente por médias e longas distâncias, motivo que justifica o foco de investigação no transporte motorizado, com destaque para o transporte público coletivo, que se torna tão relevante neste contexto. Todavia, na escala metropolitana não se pode desconsiderar o potencial dos deslocamentos não motorizados - modos ativos ou modos suaves - uma vez que também existem curtas e médias distâncias a serem percorridas, seja nas franjas entre municípios conurbados, seja com relação à intermodalidade, com o grande potencial de alimentação do sistema de transporte público coletivo.

Um dos princípios a ser incentivados nas cidades e regiões é a intermodalidade, isto é, a integração e articulação de diversos modos ao longo de um mesmo percurso. Os modos não motorizados, além de viabilizarem a intermodalidade, implicam menores investimentos, principalmente em infraestrutura física. Portanto, as condições dos deslocamentos a pé, seja para um deslocamento completo, seja para o acesso ao transporte público ou para uma mudança de modo de transporte, devem constituir uma preocupação central e prioritária nos programas e políticas relacionados à mobilidade, incluindo a escala metropolitana.

Em relação à efetiva inclusão da bicicleta como modo de transporte nas cidades e regiões, cabe destacar que esta também depende de uma política de mobilidade urbana direcionada aos modos não motorizados de transporte, atendendo aos preceitos da Lei $n^{\circ} 12.587$ (BRASIL, 2012). A bicicleta é um modo de transporte recomendável para pequenas e médias distâncias, mas, quando integrada a outros modos, permite atingir vários destinos, inclusive os de escala metropolitana. A bicicleta deve ser considerada como elemento integrante do desenho urbano nas cidades, incorporando-se a uma infraestrutura ciclável, principalmente nas áreas de baixa densidade e expansão urbana. Agrega atributos que contribuem para a equidade do uso dos espaços de mobilidade, reduz o custo nos deslocamentos, além de favorecer a saúde do usuário e a ambiência urbana. 
Para distâncias de até cinco quilômetros, nas áreas urbanas mais densas das cidades, há estudos que destacam a bicicleta como o meio de transporte mais rápido (MINISTÉRIO DAS CIDADES, 2007). Segundo o material, a bicicleta pode chegar a uma velocidade de $20 \mathrm{~km} / \mathrm{h}$, sendo sua velocidade média entre 12 e $15 \mathrm{~km} / \mathrm{h}$. O motivo do deslocamento e o tamanho da cidade influenciam fortemente a disposição dos ciclistas quanto à distância a percorrer. A competitividade da bicicleta em relação a outros modos, nas viagens urbanas de até cinco quilômetros, merece grande destaque. O Ministério das Cidades (2007) descreve 7,5 quilômetros como o raio adequado das viagens ciclísticas urbanas, que, para uma velocidade média de $15 \mathrm{~km} / \mathrm{h}$, corresponderia a uma viagem com duração de trinta minutos.

Conforme já destacado, no âmbito da intermodalidade, outra questão de suma importância relacionada à bicicleta é seu potencial de integração com o transporte coletivo. Tal integração mostra-se muito vantajosa, uma vez que a bicicleta, ao ser apropriada para pequenos e médios deslocamentos, pode alimentar o sistema de transporte coletivo, principalmente em áreas de baixa densidade, demanda ou frequência. Essa possibilidade fortalece sua viabilidade para atender deslocamentos pendulares, assim como para cobrir uma maior área da cidade, incluindo a escala metropolitana. Entretanto, para que isso se viabilize, é necessário garantir infraestrutura adequada de acesso aos nós da rede de transporte coletivo - terminais, estações e pontos de embarque e desembarque - e equipamentos e condições para sua guarda (paraciclos e bicicletários).

Na Figura 6 é possível observar que, dos 21 terminais da RMG, apenas cinco ainda não possuem bicicletários. Há uma alta taxa de ocupação dos bicicletários/dia nos terminais de Senador Canedo ( $\left.{ }^{\circ} 17\right)$, com 250, seguido do Goiânia Viva $\left(n^{\circ} 7\right)$ e Recanto do Bosque $\left(n^{\circ} 6\right)$, com sessenta. Ou seja, nesses terminais, já existe um início de experiência sobre a intermodalidade, cujo potencial é muito grande para eles e para os demais terminais. Com relação aos raios de 2,5 e 5 km, a Figura 6 mostra que grande parte da mancha urbana, principalmente nos municípios de pequeno porte, está contida nesses raios. E normalmente há áreas de expansão urbana, com baixas densidades, nas quais o transporte coletivo possui baixa frequência, tornando a bicicleta muito atrativa.

Outra questão que pode ser avaliada é a implementação de bicicletários e paraciclos em pontos de embarque e desembarque (PED), terminais e estações de conexão com grande 
demanda ou com potencial de integração por bicicleta. Dessa forma, constata-se que a intermodalidade bicicleta-ônibus tem grande potencial de alimentação dos terminais, seja no âmbito municipal, seja no metropolitano. Todavia, a implementação de uma infraestrutura ciclável de acesso aos terminais é elemento basilar para estimular esses deslocamentos e garantir segurança aos ciclistas, assim como para favorecer a intermodalidade bicicleta-transporte coletivo na RMG.

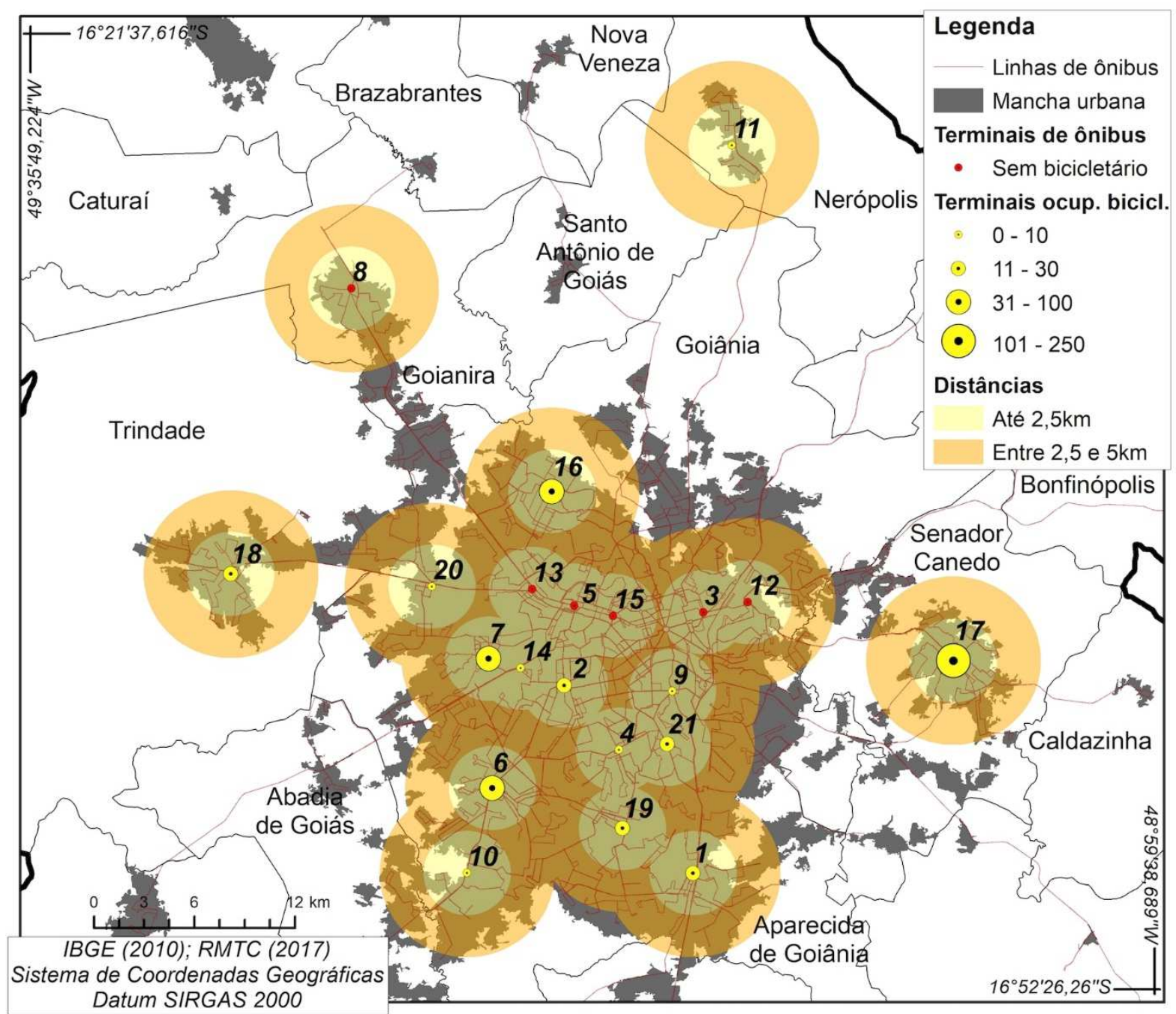

Figura 6 - Terminais com bicicletários, taxa de ocupação de bicicletas e possíveis raios de alimentação por bicicleta

Fonte: Autores, com base em dados do IBGE (2010) e RMTC (2017)

\subsection{Mobilidade na RMG: sistema viário}

O sistema viário é o espaço público por onde as pessoas circulam, a pé ou com auxílio de algum veículo (motorizado ou não), articulando, no espaço, todas as atividades humanas intra e interurbanas (MINISTÉRIO DAS CIDADES, 2015). O planejamento do sistema viário depende, em parte, das orientações e do controle sobre a distribuição das atividades 
econômicas e sociais pela cidade, mas também da construção e da organização das próprias vias. Para tal, as vias podem ser classificadas segundo sua função ou segundo uma hierarquia regional (MINISTÉRIO DAS CIDADES, 2015).

De forma complementar à classificação funcional, as vias podem ser hierarquizadas de acordo com o papel que desempenham na circulação regional, com o objetivo de coordenar a intervenção dos diversos níveis de governo no sistema viário. A administração do sistema viário é assunto de interesse local, sob responsabilidade das prefeituras. As estradas e rodovias estaduais ficam a cargo dos estados, e as federais, da União.

Em regiões com elevado grau de urbanização, como é o caso das regiões metropolitanas, é necessária uma intervenção coordenada do poder público nas três esferas, garantido o respeito à autonomia municipal. Apesar de a jurisdição dessas vias permanecer com o município, elas apresentam uma utilização diferenciada das demais vias que compõem a malha viária da cidade, decorrente de um elevado fluxo de passagem de característica metropolitana ou regional (MINISTÉRIO DAS CIDADES, 2015).

A Figura 7 apresenta as principais vias que compõem o sistema viário de interesse metropolitano da RMG. Cabe destacar que as vias que conectam os municípios e permitem os deslocamentos por transporte coletivo, bicicleta, carga e automóveis são as mesmas. Ou seja, o sistema viário metropolitano necessita ser organizado, gerido e fiscalizado de modo a buscar uma mobilidade metropolitana sustentável, na qual os preceitos da lei federal de mobilidade sejam respeitados. Sendo assim, essa caracterização deve priorizar, segundo preceitos da lei em questão, o modo coletivo sobre o individual motorizado; nos locais com necessidade de inserção de infraestrutura para bicicleta e para deslocamento e travessia de pedestres, estes devem ser tratados com toda a atenção, mesmo que isso signifique a revisão das condições de fluidez do veículo motorizado individual. Essa categorização deve ser dinâmica e permitir a inserção de novas vias segundo a necessidade. 


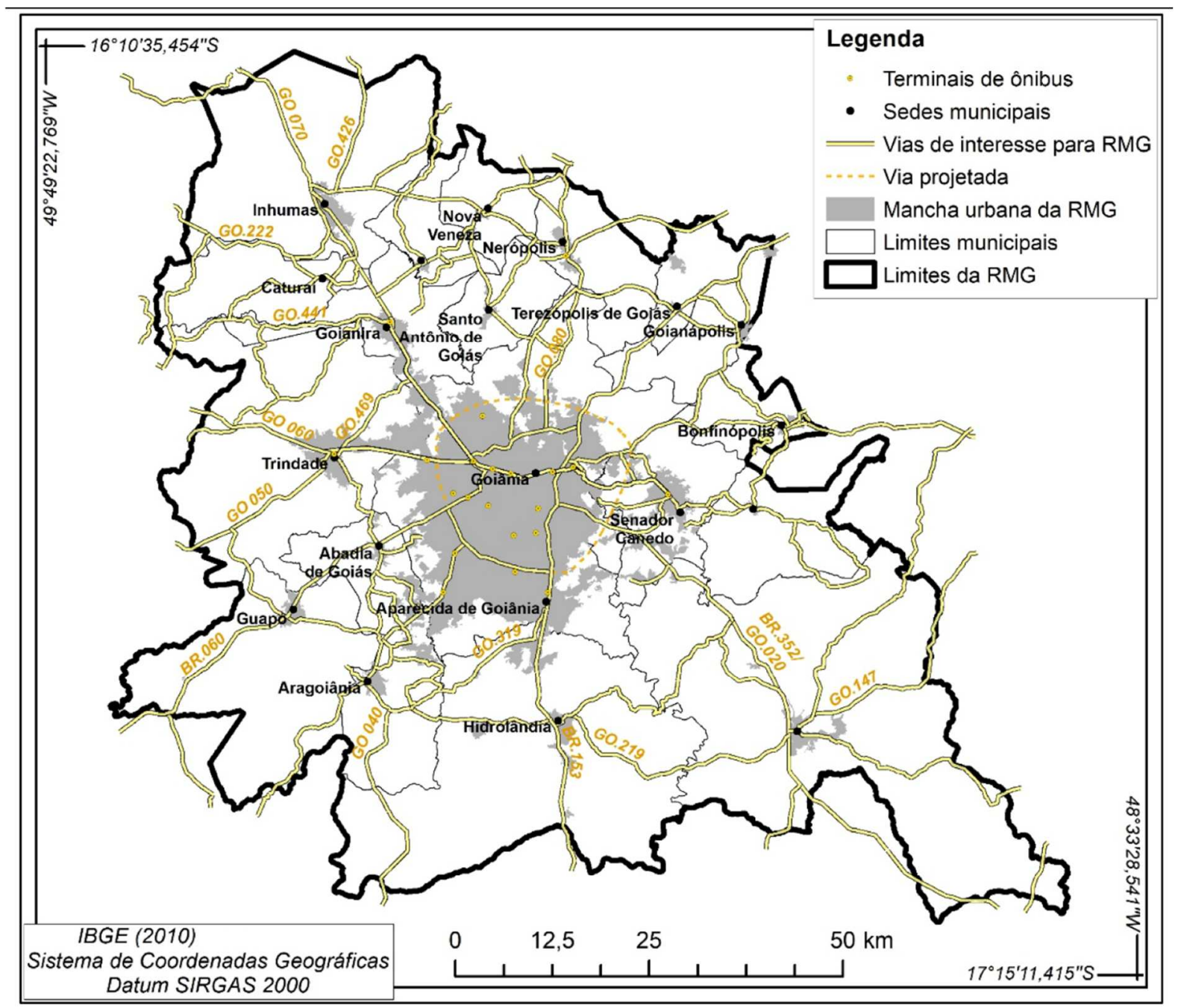

Figura 7: Sistema viário de interesse metropolitano

Fonte: Autores, com base em dados do IBGE (2010)

\section{Considerações finais: o panorama da mobilidade na RMG}

Este trabalho apresentou os principais aspectos da mobilidade na RMG, atingindo-se o objetivo proposto. Cabe enfatizar o grande desafio que foi desenvolver este panorama da mobilidade metropolitana, uma vez que praticamente não há dados atualizados sobre os deslocamentos metropolitanos na RMG, ou mesmo uma plataforma que reúna dados metropolitanos. Conforme destacado inicialmente, a última pesquisa O/D foi realizada no ano 2000 , e sabe-se da limitação de realizar um trabalho como este sem uma pesquisa O/D atualizada. Todavia, sabe-se também que nem sempre se dispõe de todos os dados necessários e atuais, sendo que este primeiro panorama, desenvolvido a partir de bases existentes, seja futuramente aprimorado e evoluído, segundo as necessidades. Assim sendo, 
após muita pesquisa, obtenção de dados secundários e manipulação das bases de dados existentes, foi possível elaborar o referido panorama.

A partir deste primeiro panorama da mobilidade na RMG, destaca-se que tais informações, além de auxiliarem o diagnóstico do PDUI, podem contribuir também para embasar diretrizes dos planos diretores municipais, dos planos de mobilidade municipais (também exigidos pela Lei Federal brasileira), mas principalmente, no contexto metropolitano, conformar um primeiro e importante passo para fomentar um processo de planejamento metropolitano de mobilidade, conformado por um plano de mobilidade metropolitano, no qual esteja inserida uma pesquisa OD metropolitana.

Para este trabalho, a partir da pesquisa bibliográfica e qualiquantitativa, foram utilizadas bases de dados diversas associadas a um SIG para as análises em questão. A divisão do tema mobilidade em subtemas - dinâmica metropolitana, transporte coletivo, motorizado individual e cargas, modos não motorizados e sistema viário - também mostrou-se de grande utilidade para compreensão do tema.

Com relação à dinâmica metropolitana, é possível concluir um grande impacto do espraiamento urbano nesta dinâmica. Existe uma alta concentração de infraestrutura urbana e atividades na capital Goiânia, seguida de Aparecida de Goiânia, Senador Canedo e Trindade, o que pode ser considerado uma fragilidade, pois gera centralidades sem equilíbrio, com grande atratividade para Goiânia, seguida dos municípios citados, produzindo uma rede urbana desequilibrada. Como consequência, verifica-se uma alta intensidade de fluxos pendulares para Goiânia e Aparecida de Goiânia, sobrecarregando os sistemas de transporte e viário, principalmente em horários de pico. Como potenciais podese elencar que os 20 municípios integrantes da RMG possuem portes diferenciados, com vocações distintas; mesmo concentrados em alguns municípios, a RMG conta com bom provimento de estabelecimentos de ensino, postos de trabalho, equipamentos de saúde; boa oferta de serviços e espaços de cultura e lazer, que pode ser utilizado para uma busca de equilíbrio desta rede urbana.

Relativo ao subtema transporte público coletivo, constata-se a perda de competitividade do TPC em relação ao modo motorizado individual, provocada por fatores como ausência de infraestrutura adequada, aumento do tempo de viagem, falta de pontualidade e 
confiabilidade, problemas com o financiamento do sistema, dentre outros, com sérias consequências para a mobilidade e para toda a sociedade metropolitana, a exemplo de perda crescente de demanda. Por outro lado, existem potenciais relacionados à existência de uma rede unificada e integrada que atende dezoito municípios da RMG e à tecnologia empregada para planejamento, que permite mapeamento dos veículos e informação ao usuário em tempo real, gerando informação ao usuário que pode ser acessada por um App, fatos estes que não são comuns nas cidades brasileiras; há uma grande cobertura espacial da rede existente nas manchas urbanas; existem debates sobre a necessidade de recursos extratarifários e de constituição de um fundo para custeio do serviço e melhoria da qualidade.

Sobre o transporte motorizado individual, observa-se que o crescimento da frota aliado às facilidades para utilização deste modo individual majora os problemas de poluição e acidentes, agrava os índices de congestionamento, ao mesmo tempo em que prejudica o transporte coletivo, mostrando que a mobilidade na RMG caminha para um modelo insustentável, demandando uma reversão de paradigma. Já o transporte de carga, tão relevante para a economia metropolitana, também carece de um planejamento setorial e de infraestrutura adequada.

O transporte não motorizado, tão destacado como prioritário na política de mobilidade brasileira, com alta potencialidade de utilização na RMG, principalmente para favorecer a intermodalidade, enfrenta falta de condições básicas, como ausência de infraestrutura, políticas e ações que viabilizem e incentivem sua utilização. Por outro lado, percebe-se o início de uma cultura para o uso da bicicleta, como a existência de algumas ciclovias na RM, a existência de um sistema de bicicletas públicas na Capital e a existência de bicicletários na maioria dos terminais de transporte coletivo.

Já o sistema viário de interesse metropolitano, de suma importância para dar suporte aos modos antes mencionados, carece de um planejamento integrado que o potencialize e que permita fomentar a utilização de modos mais adequados à mobilidade metropolitana, principalmente o transporte coletivo e a bicicleta. Como potenciais, cabe relatar que o sistema viário permite acesso e integra todos os municípios da RMG; e possui potencial para implementação de corredores para o transporte coletivo e infraestrutura cicloviária. 
Em suma, o presente panorama aponta para um cenário de grande fragilidade para a mobilidade na RMG, caso não sejam tomadas providências e atitudes concretas para tal reversão. Deste modo, a partir de constatados tais fatos, aponta-se novamente uma questão que majora a dificuldade de reversão de tal cenário: são pelo menos 42 instituições (Estado mais 20 municípios, no âmbito legislativo e executivo) que necessitam estar articuladas, integradas, trabalhando para que estes temas e os demais que impactam e são impactados pela mobilidade - uso do solo, economia, meio ambiente, dentre outros - sejam convergentes e gerem melhorias efetivas para a mobilidade metropolitana na RMG, em bases sustentáveis. Nesta situação, a efetivação de uma governança interfederativa, trazida pelo Estatuto da Metrópole, mostra-se fundamental.

Por fim, cabe destacar que o presente trabalho constitui-se um panorama inicial e importante para contribuir com as bases do diagnóstico sobre mobilidade para o PDUI da Região Metropolitana de Goiânia. Porém, deve ser destacado que, posteriormente à elaboração do presente estudo, foi aprovada a Lei Complementar 139 (Goiás, 2018), que incluiu o município de Santa Bárbara de Goiás e excluiu o de Inhumas da RMG. Destarte, tais alterações legais demandarão a atualização do presente estudo, assim como fomentarão a continuidade de pesquisas como as aqui desenvolvidas.

\section{Agradecimentos}

Os autores agradecem à professora Celene Cunha Monteiro Antunes Barreira, coordenadora do Plano de Desenvolvimento Integrado da Região Metropolitana de Goiânia, e aos pesquisadores Juheina Lacerda Viana, Ana Carolina Fernandes Pires, Antenor Pinheiro e Jaquelinne Neves de Oliveira.

\section{Referências bibliográficas}

BRASIL. Constituição da República Federativa do Brasil. 1988. Disponível em: <http://www.planalto.gov.br/ccivil_03/constituicao/constituicao.htm>. Acesso em janeiro de 2018. 
BRASIL. Lei $n^{\circ}$ 12.587, de 3 de janeiro de 2012. Institui as diretrizes da Política Nacional de Mobilidade Urbana e dá outras providências. http://www.planalto.gov.br/ccivil_03/_ato2011-2014/2012/lei/l12587.htm Diário Oficial [da] União, Brasília, DF, 4 jan. 2012.

BRASIL. Lei $n^{\circ}$ 13.809, de 3 de janeiro de 2015. Institui o Estatuto da Metrópole, altera a Lei no 10.257, de 10 de julho de 2001, e dá outras providências. http://www.planalto.gov.br/ccivil_03/ _ato20112014/2012/lei/I12587.htm Diário Oficial [da] União, Brasília, DF, 13 jan. 2015.

CMTC - COMPANHIA METROPOLITANA DE TRANSPORTES COLETIVOS. Plano Diretor de Transporte Coletivo Urbano da Grande Goiânia - PDSTC 2006. Goiânia, 2007.

CMTC - COMPANHIA METROPOLITANA DE TRANSPORTES COLETIVOS. Regulamento Operacional da Rede Metropolitana de Transportes Coletivos da Região Metropolitana de Goiânia (ROT). Goiânia, 2013. Disponível em: < http://www.sgc.goias.gov.br/upload/arquivos/2013-09/rot2.pdf>. Acesso em janeiro de 2018.

CNT - CONFEDERAÇÃO NACIONAL DO TRANSPORTE ; NTU - ASSOCIAÇÃO NACIONAL DAS EMPRESAS DE TRANSPORTES URBANOS. Pesquisa mobilidade da população urbana 2017. Brasília, DF, 2017. ISBN 978-8566881-10-3.

DENATRAN - DEPARTAMENTO NACIONAL DE TRÂNSITO. Frota de veículos. 2005. Disponível em: <http://www.denatran.gov.br/index.php/estatistica/237-frota-veiculos>. Acesso em: dezembro de 2017.

DENATRAN - DEPARTAMENTO NACIONAL DE TRÂNSITO. Frota de veículos. 2016. Disponível em: <http://www.denatran.gov.br/index.php/estatistica/261-frota-2016>. Acesso em dezembro de 2017.

ESRI. GIS Dictionary. Disponível https://support.esri.com/en/other-resources/gisdictionary/term/jenks\%27\%20optimization. Acesso em: fevereiro de 2017.

FIRJAN. Os custos dos deslocamentos nas principais áreas urbanas do Brasil. Rio de Janeiro, set. 2015.

IBGE - INSTITUTO BRASILEIRO DE GEOGRAFIA E ESTATÍSTICA. Arranjos populacionais e concentrações urbanas do Brasil. 2. ed. Rio de Janeiro: IBGE, 2016. ISBN 978-85-240-4406-9.

IMTT - INSTITUTO DA MOBILIDADE E DOS TRANSPORTES TERRESTRES. Guia para a elaboração de planos de mobilidade $\quad$ transportes. $2011 . \quad$ Disponível em: <http://www.epomm.eu/old_website/docs/2075/Guia_para_a_elaboracao_de_PMT_Marco_2011.pdf>. Acesso em janeiro de 2018.

IPEA - INSTITUTO DE PESQUISA ECONÔMICA APLICADA. Infraestrutura Social e Urbana no Brasil: subsídios para uma agenda de pesquisa e formulação de políticas públicas. Livro 6, Vol. 2. Brasília, 2010.

IPEA - INSTITUTO DE PESQUISA ECONÔMICA APLICADA. Tarifação e financiamento do transporte público urbano. Nota Técnica. Brasília, DF, 2013.

ITDP - INSTITUTO DE POLÍTICAS DE TRANSPORTE \& DESENVOLVIMENTO . Padrão de qualidade TOD (v2.0). Rio de Janeiro: ITDP, 2013.

GOIÁS. Lei complementar 27, de 30 de dezembro de 1999. Disponível em: <http://www.gabinetecivil.go.gov.br/pagina_leis.php?id=7066>. Acesso em Acesso em janeiro de 2018.

GOIÁS. Lei Complementar 139, de 22 de janeiro de 2018. Dispõe sobre a Região Metropolitana de Goiânia, o Conselho de Desenvolvimento da Região Metropolitana de Goiânia, cria o Instituto de Planejamento Metropolitano dé outras providências. Disponível em http://www.gabinetecivil.go.gov.br/pagina_leis.php?id=22493. Acesso em outubro de 2018.

GOUVÊA, R. G. A Questão Metropolitana no Brasil. Editora FGV. Rio de Janeiro, 2005.

HARVEY, D. Social Justice and the City. Oxford: Blackwell, 1973.

KNEIB, E. C. (Org.). Projeto e cidade: centralidades e mobilidade urbana. Goiânia: FAV/UFG, 2013. ISBN 978-8568359-09-9

KNEIB, E. C. (Org.). Projeto e cidade: mobilidade e acessibilidade em Goiânia. Goiânia: Ed. UFG, 2016. ISBN 978$85-495-0022-9$ 
LOBO, C., MATOS, R., CARDOSO, L., COMINI, L., PINTO, G. Expanded commuting in the metropolitan region of Belo Horizonte: evidence for reverse commuting. Rev. bras. estud. popul. vol.32 no.2 São Paulo May/Aug. 2015. http://dx.doi.org/10.1590/S0102-30982015000000013

LORENZETTI, M. S. B. Gratuidade no sistema de transporte público de passageiros. Consultoria Legislativa. Câmara Federal do Brasil. Brasília, DF, 2003.

MINISTÉRIO DAS CIDADES. PlanMob: construindo a cidade sustentável - Caderno de Referência para Elaboração de Plano de Mobilidade Urbana. Brasília, DF, 2007.

MINISTÉRIO DAS CIDADES. PlanMob: construindo a cidade sustentável - Caderno de Referência para Elaboração de Plano de Mobilidade Urbana. Brasília, DF, 2015.

MOURA, R. et al. Movimento pendular e perspectivas de pesquisas em aglomerados urbanos. São Paulo em Perspectiva, v. 19, n. 4, p. 121-133, out./dez. 2005.

NTU - ASSOCIAÇÃO NACIONAL DAS EMPRESAS DE TRANSPORTES URBANOS. Revista NTUrbano. Ano IV, número 23. Brasilia, DF, 2016.

ONU HABITAT. Nova Agenda Urbana. United Nations, 2016.

PYCA, R. Metropolization as na effective tool for fighting the recession and overcoming effects of the crisis. Forum Scientiae Oeconomia Volume 1 (2013) No 2.

RMTC - REDE METROPOLITANA DE TRANSPORTES COLETIVOS. Dados e informações sobre o transporte coletivo - RMTC: relatório técnico. Goiânia: Consórcio RedeMob, 2016.

RMTC - REDE METROPOLITANA DE TRANSPORTES COLETIVOS. Dados e informações sobre o transporte coletivo - RMTC: relatório técnico. Goiânia: Consórcio RedeMob, 2017a.

RMTC - REDE METROPOLITANA DE TRANSPORTES COLETIVOS. Informações Institucionais. 2017b. Disponível em: <http://www.rmtcgoiania.com.br/sobrea-a-rmtc/informacoes-institucionais>. Acesso em: jun. 2017.

SEPLAN (2010). Perfil competitivo das regiões de planejamento do Estado de Goiás. Gerência de Competitividade e Cadeias Produtivas, Superintendência de Planejamento e Desenvolvimento, Secretaria do Planejamento e Desenvolvimento (atual Segplan). Goiânia, 2010. Disponível em: <http://www.sgc.goias.gov.br/upload/anexos/2011- 04/f40892f24f7def77a05e7bce682943ff.pdf>. Acesso em dezembro de 2017.

SOJA, E. (1989). Postmodern Geographies: The Reassertion of Space in Critical Social Theory. London: Verso Press, 1989.

UFG E SECIMA. Plano de Desenvolvimento Integrado da Região Metropolitana de Goiânia: Diagnóstico. Universidade Federal de Goiás e Secretaria de Infraestrutura, Meio Ambiente e Recursos Hídricos do Estado de Goiás. Goiânia, Goiás, 2017. 